\title{
UVB radiation induced effects on cells studied by FTIR spectroscopy
}

\author{
Lucia Di Giambattista $\cdot$ P. Grimaldi · S. Gaudenzi • \\ D. Pozzi · M. Grandi · S. Morrone · I. Silvestri · \\ A. Congiu Castellano
}

Received: 28 January 2009 / Revised: 10 March 2009 / Accepted: 16 March 2009

(C) European Biophysical Societies' Association 2009

\begin{abstract}
We have made a preliminary analysis of the results about the effects on tumoral cell line (lymphoid $\mathrm{T}$ cell line Jurkat) induced by UVB radiation (dose of $310 \mathrm{~mJ} / \mathrm{cm}^{2}$ ) with and without a vegetable mixture. In the present study, we have used two techniques: Fourier transform infrared spectroscopy (FTIR) and flow cytometry. FTIR spectroscopy has the potential to provide the identification of the vibrational modes of some of the major compounds (lipid, proteins and nucleic acids) without being invasive in the biomaterials. The second technique has allowed us to perform measurements of cytotoxicity and to assess the percentage of apoptosis. We already studied the induction of apoptotic process in the same cell line by UVB radiation; in particular, we looked for correspondences and correlations between FTIR spetroscopy and flow cytometry data finding three highly probable spectroscopic markers of
\end{abstract}

Proceedings of the XIX Congress of the Italian Society of Pure and Applied Biophysics (SIBPA), Rome, September 2008.

L. Di Giambattista $(\bowtie) \cdot$ P. Grimaldi · S. Gaudenzi .

A. Congiu Castellano

Dipartimento di Fisica, Università di Roma Sapienza,

Piaz.le A. Moro, 2, 00185 Rome, Italy

e-mail:1.digiambattista@caspur.it

L. Di Giambattista

CISB (Interdepartmental Research Centre for Biomedical Systems

Models and Information Analysis), Rome, Italy

D. Pozzi · S. Morrone · I. Silvestri

Dipartimento di Medicina Sperimentale,

Università di Roma Sapienza, V.le Regina Elena,

324, 00161 Rome, Italy

M. Grandi

Poliambulatorio La Torre, V. M. Ponzio,10,

10141 Torino, Italy apoptosis (Pozzi et al. in Radiat Res 168:698-705, 2007). In the present work, the results have shown significant changes in the absorbance and spectral pattern in the wavenumber protein and nucleic acids regions after the treatments.

Keywords UVB radiation · FTIR spectroscopy $\cdot$ Cells . Apoptosis

\section{Introduction}

Infrared (IR) spectroscopy is a technique able to monitor the different phases of conformational and functional changes in complex biological samples, such as tissues or cell cultures. This technique allows to study the nature of the chemical bonds and their molecular environment in a given sample (Gaudenzi et al. 2004; Andrus and Strickland 1998). Our research is aimed to understand how the changes of IR spectra are correlated to different treatments, UVB radiation and a vegetable mixture, by using FTIR spectroscopy coordinated with flow cytometry and optical microscopy.

We have already made a similar study using only the UVB radiation on Jurkat cells (Pozzi et al. 2007), now we introduce a particular mixture to test a possible changes in the apoptotic process induced by UVB radiation. At present, the most medical studies are focused on control cell death because the loss of apototic process may be as important as increased cell growth in many tumors, so the medicinal natural research has introduced the use of natural compounds operating at molecular level (Chor et al. 2005).

We have chosen a natural mixture which is composed of some vegetables substances (Epilobium, Urtica dioica, and a lichen, Evernia Prunastri) in hydro-alcoholic solution. 
Lichens produce different secondary products (lichen metabolites) with filtering properties of UV radiation, in particular the phenolics metabolites that are partially secreted to lichen cortex and produced a protective screen against UV radiation (Legaz et al. 2001). By flow cytometry, we have analyzed the level of toxicity of the mixture (Tuschl and Schwab 2004) and we have established the percentage of apoptotic cells induced by UVB radiation with and without this mixture.

These our initial results have indicated that it is possible to relate the shift in the spectral signatures with the variations of the apoptotic process induced by the different treatments.

\section{Materials and method}

\section{Cells and culture conditions}

The Jurkat cells $\mathrm{CD}^{+} / \mathrm{CD} 2^{+}$, a lymphoid $\mathrm{T}$ cell line, were used for this study. Cells were cultured in RPMI 1640 medium added with $10 \%$ fetal bovine serum, $1 \%$ penicillin-streptomycin and $1 \%$ L-glutamine in humidified atmosphere (95\% air) and $5 \% \mathrm{CO}_{2}$ at $37^{\circ} \mathrm{C}$.

The unsynchronized cell population was used both for the untreated (control) and the treated sample at a routinely viability of 98\% (determined by the Trypan blue exclusion test).

\section{Cell treatment}

For our study, we used a particular mixture constituted from Epilobium, Evernia Prunastri Arch and Urtica dioica, in hydro-alcoholic solution.

The cellular samples were divided into four groups: cells irradiated with UVB, cells treated with UVB and some doses of the solution, cells treated with some doses of the solution and finally two control samples at 0 and $24 \mathrm{~h}$ after the beginning of treatment.

Preliminary test on the solution toxicity showed that doses higher than $30 \mu \mathrm{l}$ cause a toxic effect on cells. Thus, we have treated the cellular sample with the following doses: 5, 10, 20, $30 \mu$ l.

At the same time, cellular samples treated only with $5,10,20,30 \mu$ of solution and samples exposed to UVB radiation with and without the solution were placed inside the incubator and cultured for 60,210 and 360 min until the cytofluorimetric and spectroscopic measurements. The UVB exposure conditions have been the same used to induce the apoptosis ( $30 \mathrm{~cm}$ for $30 \mathrm{~min}$ ).

\section{UVB radiation}

A Philips TL20 W/12 lamp emitting $2.1 \mathrm{~W}$ at $310 \mathrm{~nm}$ was used to induce apoptosis through UVB irradiation (Novak et al. 2004). The exposure time of $30 \mathrm{~min}$ at a distance of $30 \mathrm{~cm}$, corresponding to a dose of $310 \mathrm{~mJ} / \mathrm{cm}^{2}$ (confirmed by radiometer Gigahertz-Optik GmbH, Germany) produced the maximum percentage of apoptotic cells detected by flow cytometry.

Then, control and irradiated cells were cultured in the incubator for $60,210,360 \mathrm{~min}$ before the cytofluorimetric and spectroscopic measurements.

\section{Flow cytometry}

Flow cytometry with double staining of Annexin V-FITC/ (PI) propidium iodide was performed to detect both apoptosis and necrosis. The percentage of apoptotic cells was determined by green fluorescence emitted by Annexin V-FITC bound to phosphatidylserine that is exposed to the outer leaflet of the membrane of apoptotic cells, while propidium iodide detects necrotic cells in the samples. Before the measurements, $1 \times 10^{6}$ cells were extensively washed in (PBS) Phosphate buffered saline, rinsed with Hepes buffer, resuspended in the same buffer, and incubated at room temperature for 5-15 min in the dark after the addition of Annexin V-FITC; just before the measurements, PI was added to the cell suspension.

The cytofluorimetric analysis was performed using a FACSCalibur (BD Biosciences, San Jose, CA) equipped with an argon-ion laser at an optimal excitation wavelength of $488 \mathrm{~nm}$.

The PI intercalated into DNA, after spontaneously going into the cells, allow us to detect the toxicity threshold of mixture dose (Di Pietro et al. 2005). These measures were performed adding $10 \mu \mathrm{l}$ of PI solution $(10 \mathrm{mg} / 100 \mathrm{ml}$ PBS $)$ before cytometry detection.

\section{Optical microscopy}

The morphological changes in cellular samples were detected through a Leica DMIL microscope equipped with a digital camera Olympus for the acquisition of frames. Cell images were acquired using a $40 \times$ magnification at 60 , 210, 360 min after the treatments, placing the cells, with their culture medium, in uncovered culture plates.

\section{FTIR spectroscopy}

Cell spectra were collected using an FTIR/410 Jasco Fourier Transform IR spectrometer equipped with an ATRPRO410-S single reflection ATR accessory with a $45^{\circ}$ single reflection $\mathrm{ZnSe}$ horizontal crystal plate.

Measurements were performed at room temperature using a conductive ceramic coil mounted in a water-cooled copper jacket source, a $\mathrm{KBr}$ beam splitter, an optical path purged continuously with gaseous nitrogen and a TGS detector. 
Table 1 Comparison of the percentage of viable cells at 0 and $24 \mathrm{~h}$ for different treatments (mixture and UVB)

\begin{tabular}{lcll}
\hline Treatment & Doses & \multicolumn{2}{l}{$\%$ Viable cells } \\
\cline { 3 - 4 } & & $0(\mathrm{~h})$ & $24(\mathrm{~h})$ \\
\hline Mixture $(\mu \mathrm{l})$ & 5 & 89 & 87 \\
& 10 & 89 & 87 \\
& 20 & 89 & 88 \\
UVB Radiation $\left(\mathrm{mJ} / \mathrm{cm}^{2}\right)$ & 30 & 89 & 88 \\
\hline
\end{tabular}

For each spectrum, a resolution of $4 \mathrm{~cm}^{-1}$ was used, 64 interferograms were coadded and apodized with a triangular function. ATR penetration depth compensation, was performed by using the Spectral Manager Analysis software.

Then, all IR spectra were studied in the spectral region from 1,760 to $900 \mathrm{~cm}^{-1}$, baseline corrected and intensity normalized at $1,541 \mathrm{~cm}^{-1}$; the experimental data were processed by using Microcal Origin 7.5 software. Three runs of FTIR, flow cytometry and microscopy experiments were performed.

\section{Results and discussion}

Flow cytometry

To quantify the toxicity of the treatments (mixture dose and UVB radiation), we have assessed the viability of cell population with PI: this marker is a DNA intercalating dye that is excluded by cells that have their plasma membrane integrity preserved (live cells), but it enters and stains DNA in cells that have damaged membranes, necrotic cells (Table 1).

The sample treated with mixture reveals no toxic effect up till $30 \mu \mathrm{l}$ dose from 0 to $24 \mathrm{~h}$, while the percentage of viable cells decreases at $24 \mathrm{~h}$ for UVB-treated sample. To assess the apoptosis, we have used FITC-coniugated Annexin V and PI.

In Fig. 1, we have reported the most significant results for treated cells with a dose of $30 \mu \mathrm{l}$ (Van Engeland et al. 1998).

This analysis has shown how the mixture at different doses has modified the effect of UVB radiation between 0 and $6 \mathrm{~h}$.

Finally, the experimental data were analyzed by repeated measures ANOVA. Through a Fisher-Test and the degrees of freedom $\left(F_{(3,12)}\right)$ of Fisher distribution, we have evaluated and compared the FRatio $(R)$ with FRatio* $\left(R^{*}\right)$ deducing by fixed significance level $\alpha$. The results show a significant difference between the treatments $\left(R^{*}=3.49\right.$,

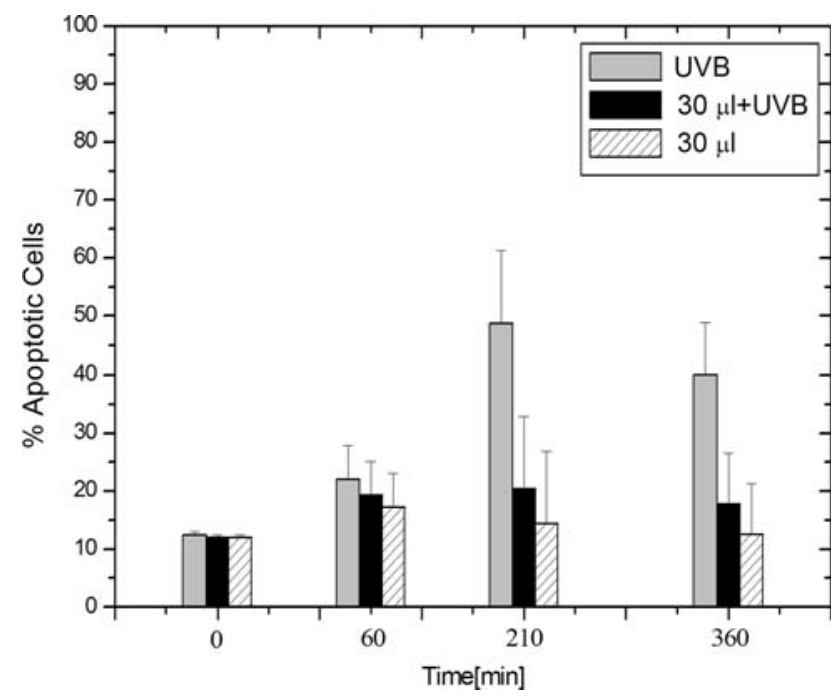

Fig. 1 Comparison of the percentage of apoptotic cells as a function of time $(0-6 \mathrm{~h})$ for the samples treated with and without the UVB radiation

$R=10.15 p \leq 0.0013$ for live, $R=11.67 p \leq 0.001$ for early apoptosis and $R=4.45 p \leq 0.002$ for late apoptosis).

\section{Optical microscopy}

To understand the effects of the treatments on the sample, we have observed the cellular morphology of the untreated and treated samples by the optical microscopy. The morphological changes are mainly due to UVB radiation. We have acquired the cellular images at $210 \mathrm{~min}$ after the treatment when we have observed the maximum of the early apoptotic process (Fig. 2).

As shown in Fig. 2 with white arrows, the apoptotic bodies are present only in the sample treated with UVB (Fig. 2b) and in the sample with mixture plus UVB (Fig. 2d) (Fadeel and Orrenius 2005).

\section{FTIR spectroscopy}

In this preliminary study, we have shown the spectrum of the control sample only in the wavenumber ranges from 1,800 to $900 \mathrm{~cm}^{-1}$ (Fig. 3); in Table 2, we have reported the assignments of commonly found absorption peaks in the IR spectra of cells (Jamin et al. 2003).

In particular, we have studied proteins (Amide I and Amide II bands centered at $1,646 \mathrm{~cm}^{-1}$ and $1,541 \mathrm{~cm}^{-1}$, respectively), and nucleic acids $\left(1,300-1,000 \mathrm{~cm}^{-1}\right.$ and $1,000-950 \mathrm{~cm}^{-1}$ ) regions. All FTIR spectra exhibited a good signal-to-noise ratio and were highly reproducible.

The following spectroscopic shift peaks were analyzed:

- $\alpha$-helix (a component of the band $\mathrm{A}_{1}$ )

- $\mathrm{P}_{3}$ (asymmetric phosphate stretching vibrations) 
Fig. 2 The images of the cells at 210 min with $\times 40$ magnifications: a untreated cells (control), b cells irradiated by UVB radiation, c cells treated with $30 \mu \mathrm{l}$ of the mixture, $\mathbf{d}$ cells treated with $30 \mu \mathrm{l}$ of the mixture plus UVB radiation. In $\mathbf{b}-\mathbf{d}$, the arrows indicate the apoptotic bodies which are absent in $\mathbf{a}-\mathbf{c}$
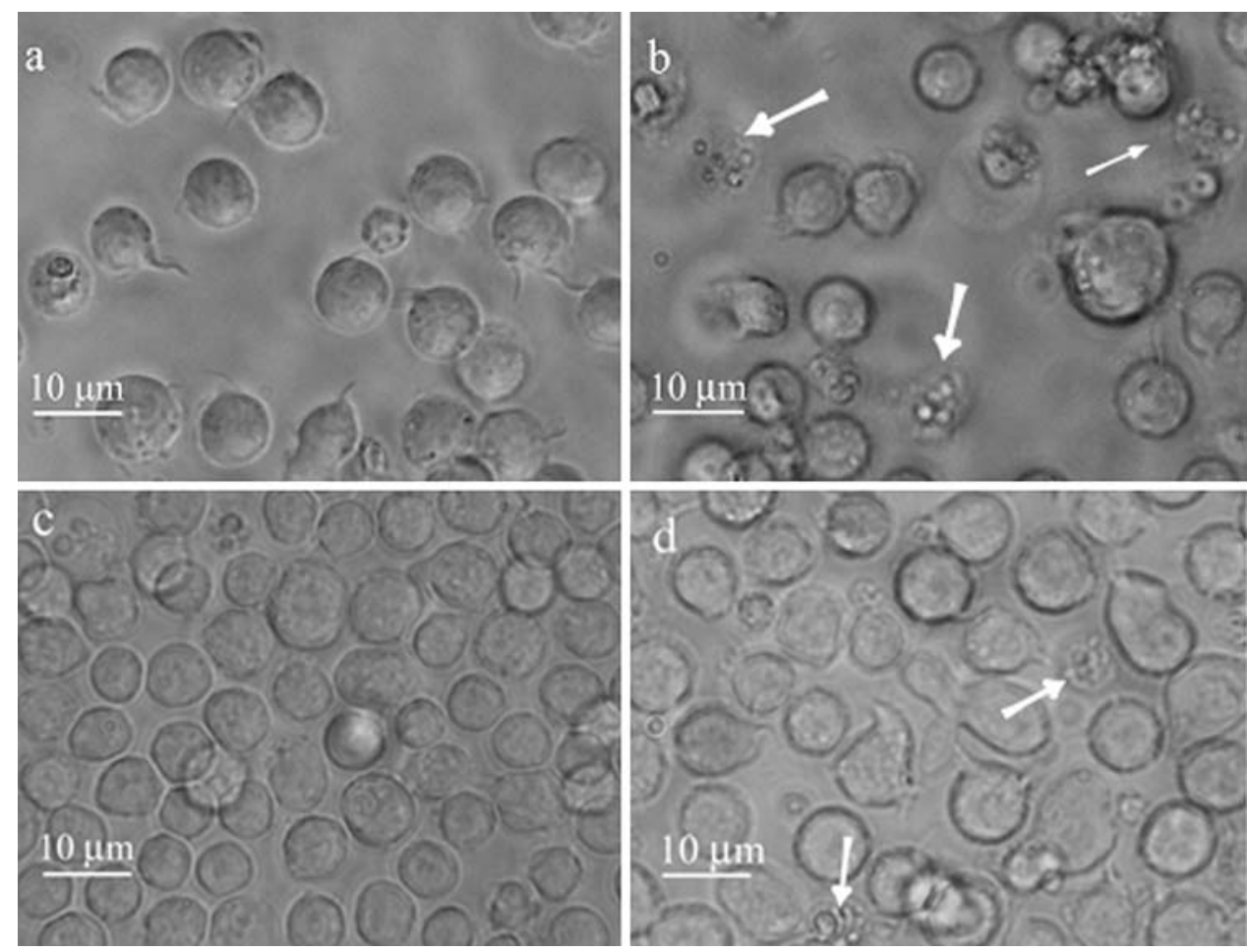

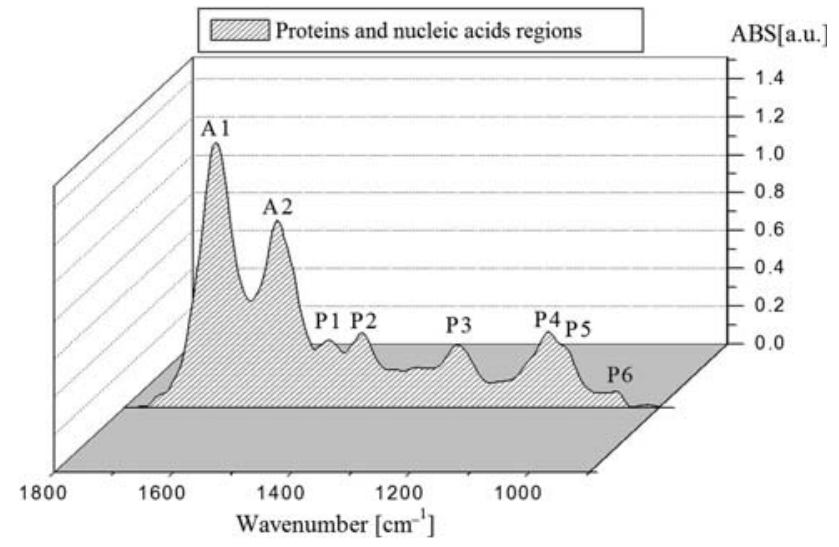

Fig. 3 IR spectra of the control sample: proteins and nucleic acids regions

Proteins and nucleic acids

The region from 1,800 to $1,480 \mathrm{~cm}^{-1}$ is dominated by the absorption modes of Amide I (Al) centered at $1,646 \mathrm{~cm}^{-1}$ and Amide II (A2) at $1,541 \mathrm{~cm}^{-1}$ which originate from the vibrations of the amide groups ( $\mathrm{CO}-\mathrm{NH})$. The shape of the Amide I band is influenced by the overlap of secondary structure of proteins: these components are $\alpha$-helix between 1,645 and $1,666 \mathrm{~cm}^{-1}, \beta$-sheets between 1,613 and $1,637 \mathrm{~cm}^{-1}, \beta$-turns between 1,666 and $1,682 \mathrm{~cm}^{-1}$ and random coil between 1,637 and $1,645 \mathrm{~cm}^{-1}$. The behavior of the $\alpha$-helix band $\left(1,664 \mathrm{~cm}^{-1}\right)$ seems to be particularly
Table 2 Representative frequencies and assignments of the major vibrational bands in FTIR spectra of cells

\begin{tabular}{|c|c|}
\hline $\begin{array}{l}\text { Absorption } \\
\text { bands }\left(\mathrm{cm}^{-1}\right)\end{array}$ & Assignments \\
\hline $1,646(A 1)$ & Amide $\mathrm{I}(-\mathrm{C}=\mathrm{O}$ stretching $)$, proteins \\
\hline $1,541(A 2)$ & Amide II ( $-\mathrm{N}-\mathrm{H}$ bending, $-\mathrm{C}-\mathrm{N}$ stretching), proteins \\
\hline $1,454(P 1)$ & $\begin{array}{l}-\mathrm{CH}_{2} \text { scissoring/- } \mathrm{CH}_{3} \text { asymmetric bending, } \\
\text { proteins, lipids }\end{array}$ \\
\hline $1,399(P 2)$ & $-\mathrm{COO}^{-}$symmetric stretching, proteins, lipids \\
\hline $1,244(P 3)$ & $\begin{array}{l}-\mathrm{PO}_{2}^{-} \text {asymmetric stretching, nucleic acids, } \\
\text { phospholipids }\end{array}$ \\
\hline $1,085(P 4)$ & $\begin{array}{l}-\mathrm{PO}_{2}^{-} \text {symmetric stretching, nucleic acids, } \\
\text { phospholipids }\end{array}$ \\
\hline $1,050(P 5)$ & $-\mathrm{C}-\mathrm{O}-$ stretching, carbohydrates \\
\hline $967(P 6)$ & $-\mathrm{PO}_{4}^{-}$symmetric stretching, nucleic acids \\
\hline
\end{tabular}

significant in the cells treated with mixture and UVB radiation (Gault and Lefaix 2003).

As shown in Fig. 4, it is possible to observe a correspondence between the shift of this spectral component and the apoptotic process induced by UVB radiation in presence of the mixture (Hagenhofer et al. 1998). The correlation between the $\alpha$-helix shift and the percentage of apoptotic cells shows that the resulting Pearson's correlation coefficients are 0.95 for UVB-treated sample and 0.91 for mixture + UVB-treated sample ( $R$-value), indicating a probability for both samples of about $99 \%$ (Fisher-Test) for the significance of the linear regression. So, we have 


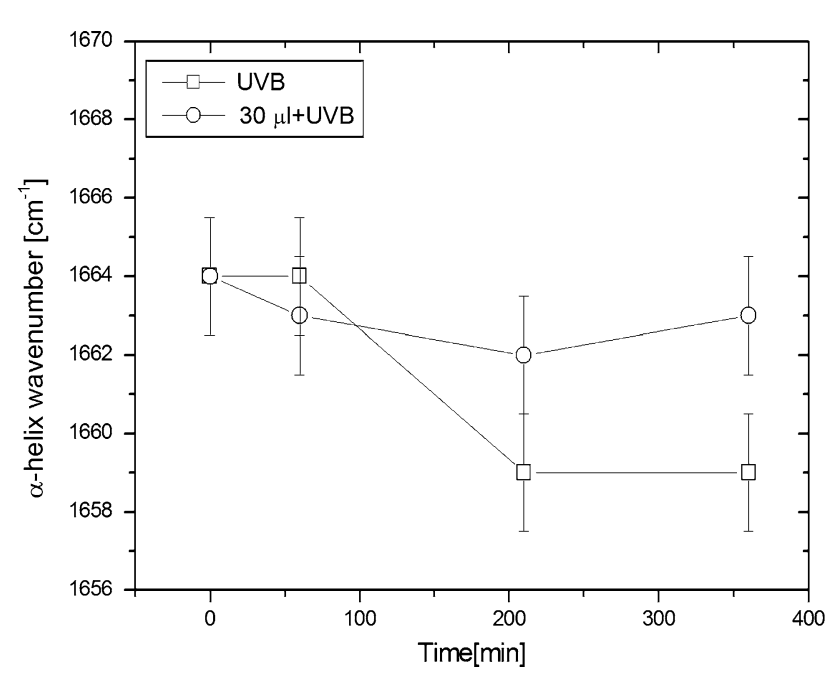

Fig. 4 Shift of the $\alpha$-helix spectral component for the followings samples: UVB, mixture plus UVB
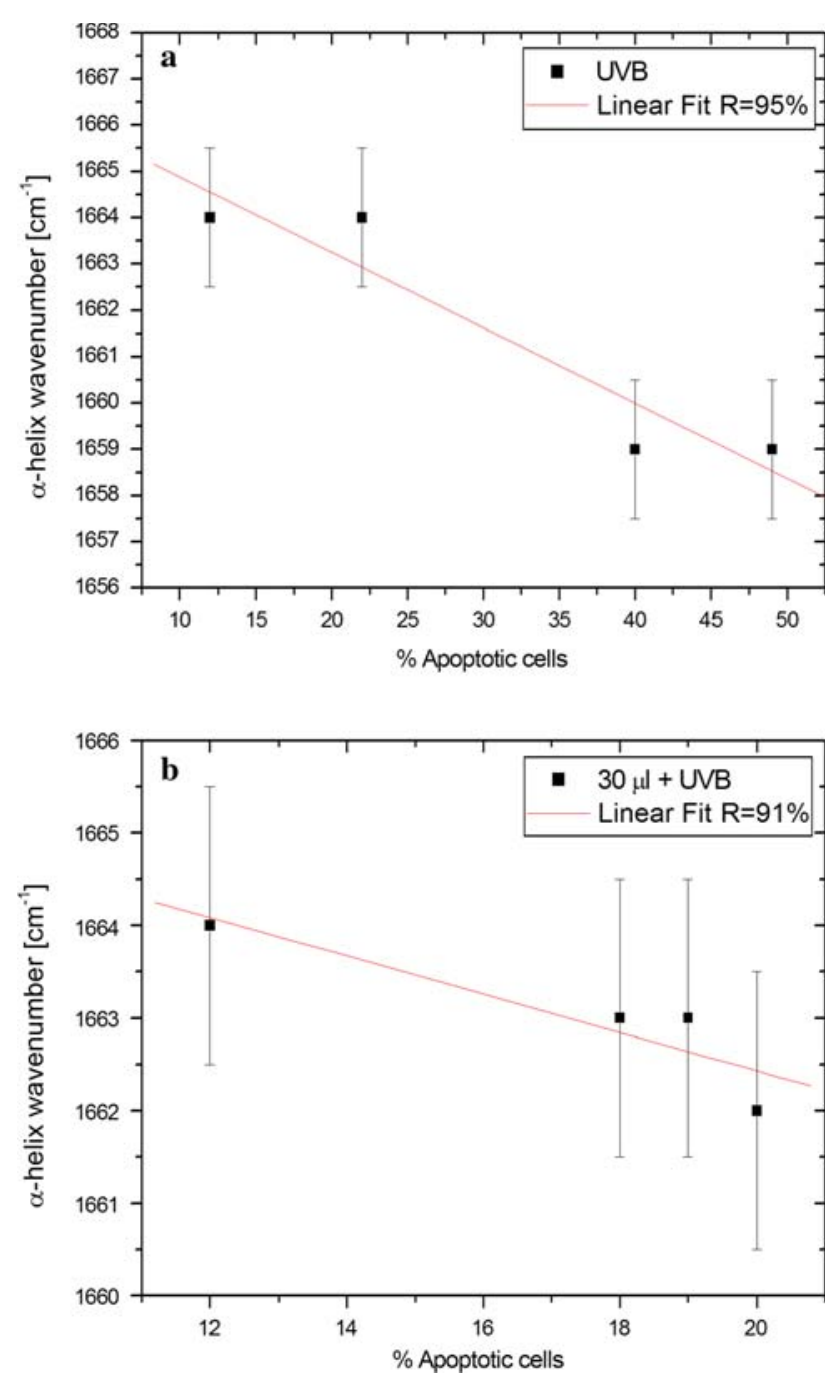

Fig. 5 a-b Linear correlation between the $\alpha$-helix shift and the percentage of apoptotic cells

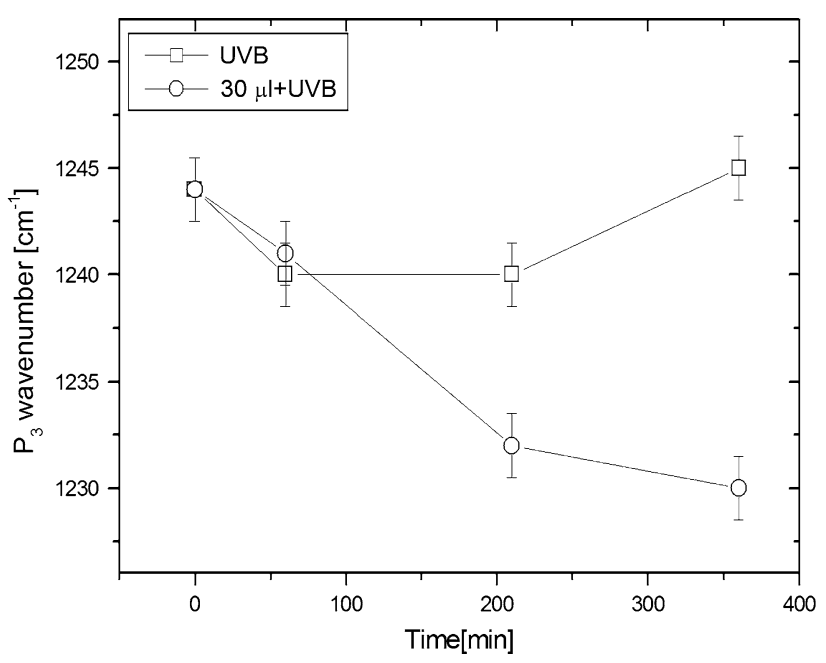

Fig. 6 Shift of the spectral band of RNA/phosphodiester groups

believed that the shift of the $\alpha$-helix can be defined as a "spectroscopic biomarker" of the increase of structural disorder induced by UVB radiation that the mixture can only delay (Fig. 5).

In the region of nucleic acids $\left(1,300-900 \mathrm{~cm}^{-1}\right)$ significant changes were observed in the cellular sample in correspondence of the band centered at $1,244 \mathrm{~cm}^{-1}$ which originates primarily from the nucleic acid phosphodiester groups of the RNA (Fig. 6) (Ravant et al. 2001).

The wavenumber of this spectral band has undergone change between 0 and $360 \mathrm{~min}$, in particular: at $210 \mathrm{~min}$ we have observed a significant shift of about $13 \mathrm{~cm}^{-1}$ to asymmetric $\mathrm{PO}_{2}^{-}$stretching of the DNA for a sample treated with the mixture plus UVB radiation which has shown a value of the percentage of apoptotic cells lower than the value of the cells treated with UVB radiation.

At the time of $360 \mathrm{~min}$ when we observe the reduction of the percentage of apoptotic cells, in UVB treated sample the $\mathrm{P}_{3}$ shift is lost while in the presence of the mixture we observe or a permament shift or a delay of the effect of the UVB radiation.

\section{Conclusions}

In the present work, we have studied the behavior of the Jurkat cells treated with a vegetable mixture and UVB radiation. We have evaluated a biomarker $(\alpha$-helix spectral component) derived from FTIR spectroscopic measurements which could be suitable for monitoring the degree of molecular disorder induced by UVB radiation. The observed spectral features are important for an understanding of the spectral differences between the cellular sample treated with and without the mixture. We underline that these results concern the experiment on cells in vitro. 
Therefore, further measurements are in progress in order to better investigate the spectroscopic behaviours emerged in the current analysis.

Acknowledgments We are grateful to Prof. M. Severini for the supply of the UVB radiation source and to Dr. Stefano Belardinelli for his assistance in the laboratory experiments.

\section{References}

Andrus PG, Strickland RD (1998) Cancer grading by Fourier transform infrared spectroscopy. Biospectroscopy 4:37-46. doi:10.1002/(SICI)1520-6343(1998)4:1<37::AID-BSPY4>3. $0 . \mathrm{CO} ; 2-\mathrm{P}$

Chor SY, Hui AY, To KF, Chann KK, Go YY, Chan HLY, Leung WK, Sung JJY (2005) Anti-proliferative and pro-apoptotic effects of herbal medicine on hepatic stellate cell. J Ethnopharmacol 100:180-186. doi:10.1016/j.jep.2005.02.036

Di Pietro C, Piro S, Tabbì G, Ragusa M, Di Pietro V, Zimmitti V, Cuda F, Anello M, Consoli U, Salinaro ET, Caruso M, Vancheri C, Crimi N, Sabini MG, Cirrone GAP, Raffaele L, Privitera G, Pulvirenti A, Giugno R, Ferro A, Cottone G, Lo Nigro S, Purrello R, Purrello F, Purrello M (2005) Cellular and molecular effects of protons: apoptosis induction and potential implications for cancer therapy. Apoptosis 11:57-66. doi:10.1007/s10495005-3346-1

Fadeel B, Orrenius S (2005) Apoptosis: a basis biological phenomena with wide-ranging implications in human disease. J Int Med 258:479-517. doi:10.1111/j.1365-2796.2005.01570.x

Gaudenzi S, Pozzi D, Toro P, Silvestri I, Morrone S, Congiu Castellano A (2004) Cell apoptosis specific marker found by Fourier transform infrared spectroscopy. Spectrosc Int J 18:415-422
Gault N, Lefaix J (2003) Infrared microspectroscopic characteristics of radiation-induced apoptosis in human lymphocytes. Radiat Res 160:238-250. doi:10.1667/RR3020.1

Hagenhofer M, Germaier H, Hohenadl C, Rohwer P, Kalden JR, Herrmann M (1998) UVB irradiated cell lines execute programmed cell death in various forms. Apoptosis 3:123-132. doi:10.1023/A:1009601109509

Jamin N, Miller L, Moncuit J, Fridman WH, Dumas P, Teillaud JL (2003) Chemical heterogeneity in cell death: combined synchrotron IR and fluores-cence microscopy studies of single apoptotic and necrotic cells. Biopolym Biospectrosc 72:366-373. doi:10.1002/bip.10435

Legaz M-E, Vicente C, Pedrosa MM (2001) Binding of lichen phenolics to purified secreted arginase from the lichen Evernia prunastri. J Biochem Mol Biol 34:194-200

Novak Z, Bérces A, Rontó G, Pállinger E, Dobozy A, Kemény L (2004) Efficacy of different UV-emitting light sources in the induction of T-cell apoptosis. J Photochem Photobiol 79:434439. doi:10.1562/RA-003R.1

Pozzi D, Grimaldi P, Gaudenzi S, Di Giambattista L, Silvestri I, Morrone S, Congiu Castellano A (2007) UVB induced apoptosis in Jurkat cells: a coordinated FTIR spectroscopy-flow cytometry study. Radiat Res 168:698-705. doi:10.1667/RR0991.1

Ravant JL, Douki T, Cadet J (2001) Direct and indirect effects of UV radiation on DNA and its components. J Photochem Photobiol 63:88-102. doi:10.1016/S1011-1344(01)00206-8

Tuschl H, Schwab CE (2004) Flow cytometric methods used as screening tests for basal toxicity of chemicals. Toxicol In Vitro 18:483491. doi:10.1016/j.tiv.2003.12.004

Van Engeland M, Nieland LJW, Ramaekerss FCS, Schutte B, Reutelingsperger CPM (1998) Annexin V-affinity assay: a review on an apoptosis detection system based on phosphatidylserine exposure. Cytometry 31:1-9. doi:10.1002/(SICI)1097-0320 (19980101)31:1<1::AID-CYTO1>3.0.CO;2-R 